JMI Vol. 39 No. 2 Desember 2017

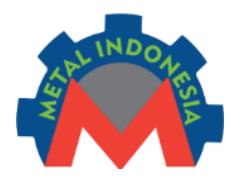

METAL INDONESIA

Journal homepage:

http://www.jurnalmetal.or.id/index.php/jmi

p-issn : $0126-3463$

e-issn : $2548-673 \mathrm{X}$

\title{
PENGUJIAN MESIN GRADING BUAH MANGGIS TIPE PIRINGAN
}

\section{TESTING OF GRADING MACHINE DISC TYPE OF MANGOSTEEN FRUIT}

\author{
Trismiyati, Sina Jamilah, Hendri Siswanto, Nur Islami Dewi, Robby Debriand Rumbara, \\ Muhammad Yudha Prawira \\ Balai Besar Logam dan Mesin \\ Kementerian Perindustrian \\ Jalan Sangkuriang Nomor 12 Bandung \\ email : trismiyati@kemenperin.go.id, sina-jamilah@kemenperin.go.id, banghendribanget@gmail.com, \\ ab_mapo@yahoo.com,robby-debriand@kemenperin.go.id, myprawira92@gmail.com
}

\begin{abstract}
Abstrak
Buah manggis merupakan salah satu jenis buah tropis. Hasil panen buah manggis dipisahkan antara yang baik dan tidak, serta di-grading berdasarkan ukuran. Grading dilakukan petani atau pedagang secara manual dengan SOP yang ada. Waktu, energi, dan biaya yang besar diperlukan untuk teknik ini. Karena itu perlu dilakukan mekanisasi proses grading. Telah dilakukan kajian penelitianpenelitian mekanisasi grading buah manggis dengan berbagai tipe termasuk piringan. Selain itu juga dilakukan survey lapangan ke dinas terkait. Dari hasil kajian, survey, maka dilakukan penelitian rancang bangun dan pengujian mesin grading tipe piringan dengan grade buah manggis adalah A dengan diameter (D) $>64 \mathrm{~mm}$, AA dengan $53 \mathrm{~mm}<\mathrm{D} \leq 64 \mathrm{~mm}$, dan AAA dengan $\mathrm{D} \leq 53 \mathrm{~mm}$. Pengujian dilakukan dengan variasi kecepatan putar piringan. Hasil yang terbaik adalah pada putaran piringan 68,4 rpm. Dengan putaran piringan tersebut, diperoleh kapasitas mesin rata-rata senilai $641,015 \mathrm{~kg} / \mathrm{jam}$. Hasil pengujian menunjukkan bahwa prototipe mesin grading buah manggis sudah dapat berfungsi memisahkan buah manggis sesuai dengan grade-nya. Rasio kontaminasi rata-rata grading sebesar 31,6\% dengan standar deviasi $12,46 \%$. Hasil penelitian ini dapat digunakan untuk penelitian lebih lanjut sehingga bisa digunakan oleh petani, pedagang, dan industri mesin serta industri kecil dan menengah pengolah buah manggis di Indonesia.
\end{abstract}

Kata kunci : Manggis, grading, diameter, kapasitas mesin, rasio kontaminasi

\begin{abstract}
Mangosteen fruit is one type of tropical fruit. Harvested mangosteen fruits are separated between good and no good, and graded by size. Grading done farmers or traders manually based on existed SOPs. Great number of time, energy, and cost are required for this technique. Therefore it is necessary to mechanize the grading process. A study of mechanized grading of mangosteen fruit with various types including piringan has been done. In addition, field surveys were also conducted to relevant offices. From the result of study and survey, construction of disc-type grading machine of mangosteen fruit grades are $A$ with diameter $(D)>64 \mathrm{~mm}$, AA with $53 \mathrm{~mm}<D \leq 64 \mathrm{~mm}$, and $A A A$ with $D \leq 53 \mathrm{~mm}$ is done. Testing is done by varying the disc rotation speed. The best disc rotation speed is at 68.4 rpm. By applying the best rotation speed, we obtain the average machine capacity of $641.015 \mathrm{~kg} / \mathrm{hour}$. The test results show that the mangosteen grading machine prototype is able to function separating the mangosteen fruit according to its grade. There is an average of grading contamination ratio of $31.6 \%$ with standard deviation of $12.46 \%$. The results of this study can be used for further research that can be used by farmers, traders, and industrial machinery and mangosteen processing of small and medium industry in Indonesia.
\end{abstract}

Keywords : Mangosteen, grading, diameter, engine capacity, contamination ratio 


\section{PENDAHULUAN}

Dalam periode 2010-2014 manggis merupakan komoditi ekspor holtikultura terbesar setelah mangga (Kementan RI 2014). Rata-rata pertumbuhan produksinya adalah sebesar 13,82 $\%$.

Buah manggis merupakan salah satu jenis buah tropis. Hasil panen buah manggis dipisahkan antara yang baik dan tidak, serta di-grading berdasarkan ukuran. Grading dilakukan petani atau pedagang secara manual dengan SOP yang ada. Waktu, energi, dan biaya yang besar diperlukan untuk teknik ini. Karena itu perlu dilakukan mekanisasi proses grading.

Kode ukuran ditentukan bedasarkan bobot atau diameter maksimum buah yang diukur secara melintang, sesuai dengan Tabel I dan II (Badan Standardisasi Nasional 2009).

Tabel 1. Kode Ukuran berdasarkan Bobot (Badan Standardisasi Nasional 2009)

\begin{tabular}{|r|l|}
\hline Kode ukuran & Bobot (gram) \\
\hline 1 & $>125$ \\
2 & $101-125$ \\
3 & $76-100$ \\
4 & $51-75$ \\
5 & $30-50$ \\
\hline
\end{tabular}

Tabel 2. Kode Ukuran berdasarkan Diameter (Badan Standardisasi Nasional 2009)

\begin{tabular}{|r|l|}
\hline Kode ukuran & Diameter $(\mathbf{m m})$ \\
\hline 1 & $>62$ \\
2 & $59-62$ \\
3 & $53-58$ \\
4 & $46-52$ \\
5 & $38-45$ \\
\hline
\end{tabular}

Keseragaman merupakan salah satu kebutuhan konsumen dan perdagangan termasuk keseragaman ukuran (Fager 1918). Berikut ini hasil penelitian Fager (1918). Efisiensi mesin grading tertinggi untuk buah terbesar, efisiensi menurun dengan menurunnya ukuran buah. Semakin cepat belt grading semakin besar tingkat kesalahan grading. Prosentase error rata-rata meningkat dengan meningkatnya kecepatan belt mesin grading. Prosentase error rata-rata grading ukuran mesin grading Trescott bervariasi dari $13,07 \%$ sampai $35,21 \%$ tergantung pada ukuran buah, kecepatan belt grading dan kecepatan buah masuk ke belt grading. Ketepatan ukuran dalam mesin grading menunjukkan bahwa grading ukuran berat lebih efisien.

Para peneliti telah melakukan penelitian desain dan pengujian mesin grading buah manggis berdasar ukuran (Jarimopas, Inprasit, and Toomsaengtong 2007). Penelitian ini mengembangkan mesin pengukur buah manggis dengan piringan berputar untuk pengusaha kecil dan menengah( Gambar 1).

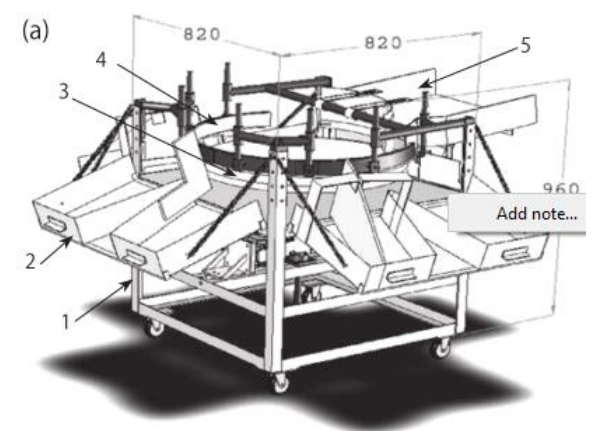

Gambar 1. Diagram Skematik Mesin Sizing Manggis

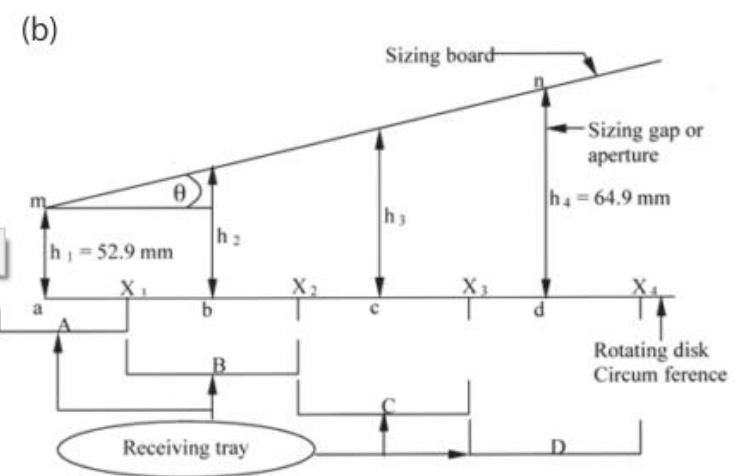

1: Frame, 2: Receiving tray, 3: Rotating disk, 4: Sizing board, 5: Feeding tray

Gambar 2. Diagram Skematik Mesin Sizing Manggis

Gambar 1. mesin terdiri dari piringan berputar , papan ukuran, baki umpan, baki penerima, dan daya penggerak, semuanya menempel pada rangka baja, di atas empat roda kecil. Gambar 2. gambaran keliling piringan sebagai garis (Jarimopas, Inprasit, and Toomsaengtong 2007). Hasil pengujian prototipe laboratorium menunjukkan bahwa ada dua faktor kendali yang mempengaruhi rasio kontaminasi $\left(\overline{C_{R}}\right)$, efisiensi ukuran $\left(E_{w}\right)$ dan kapasitas $(\mathrm{Q})$, dengan $5 \%$ diterima. Dua faktor tersebut adalah kecepatan putar piringan dan tipe ukuran celah. Kecepatan putar yang paling efisien adalah 21 rpm dengan step-type aperture, $\overline{C_{R}}$ rata-rata $14,7 \%, E_{w}=84 \%, \mathrm{Q}=1.076,6 \mathrm{~kg} / \mathrm{jam}$. 
Mesin grading dengan mekanisme rotasi juga telah dikembangkan untuk buah jeruk (Tabatabaekoloor and Hashemi 2008).

Berdasarkan SOP budidaya buah manggis kabupaten Bandung Barat, setelah buah dipanen maka dilakukan kegiatan sebagai berikut (-, 2013):

1. Manggis dikumpulkan di wadah yang bersih dan disimpan di gudang

2. Sortasi buah yang baik dan yang tidak baik

3. Grading berdasarkan ukuran (grade), Grade A: 6-8 buah per kg, Grade AA: 10-13 buah per kg, grade AAA: $14-15$ buah per $\mathrm{kg}$

4. Pencucian buah manggis dengan air untuk membersihkan buah dari kotoran dan dilap dengan hati-hati agar sepal tetap utuh

5. Pelabelan

Pelabelan pada kemasan sebagai identitas produk (berat bersih, grade buah, tanggal pengemasan)

Stiker kecil ditempelkan pada buah sebagai identitas kelas, nama produsen serta asal buah

6. Pengemasan

7. Penyimpanan

Perusahaan peralatan grading buah di China sebagian besar mengembangkan mesin grading bidang mekanik termasuk grading ukuran (Gao, Cai, and Liu 2010).

Para peneliti telah menganalisis model matematik gerak dan massa buah pada sizing machine yang ditunjukkan pada Gambar 3 (Markovic et al. 2014). Pengaruh geometrik dan parameter konstruksi pada mesin dapat diketahui secara transparan, antara lain seperti: rasio batas $\left(k_{e}\right)$, rasio pengumpan $\left(k_{f}\right)$, dan rasio distribusi $\left(k_{d}\right)$ (Markovic et al. 2014). Proses sizing buah dengan mesin memungkinkan buah rusak atau memar karena terpukul atau terbentur, sedangkan pada buah beku memungkinkan buah menjadi retak. Dalam usaha meminimalisasi permasalahan pada kedua kasus tersebut, diperlukan optimasi kecepatan piringan dan kapasitas ukuran mesin sehingga proses sizing seefisien mungkin dengan kerusakan buah sekecil mungkin. Nilai optimasi diperoleh dengan nilai $\mathrm{k}_{\mathrm{e}}=0,7, \mathrm{k}_{\mathrm{f}}=1$, $\mathrm{k}_{\mathrm{d}}=0,5$. Nilai ini sesuai dengan yang dilaporkan sampai saat ini untuk tingkat kuantitas massa buah pada ukuran mesin. Ditemukan bahwa kecepatan massa buah bervariasi, hal ini tergantung pada diameter dan massa buah. Jumlah kuantitas massa berkisar dari 8.949 tanaman/jm apel sampai 40.157 tanaman/jm untuk raspberry beku. Kecepatan massa bervariasi dari $229,1 \mathrm{~kg} / \mathrm{jam}$ untuk cherry sampai 2.054,7 kg/jam untuk apel (Markovic et al. 2014).

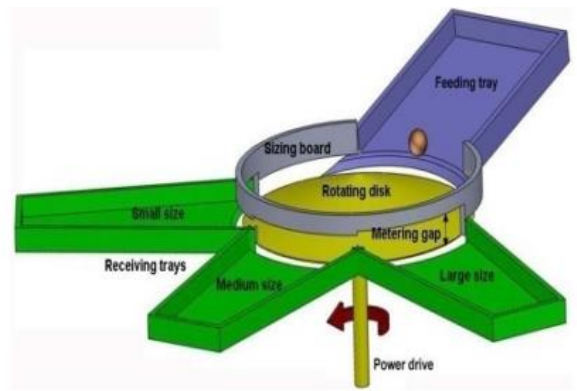

Gambar 3. Diagram skematik sizing machine buah (Markovic et al. 2014)

Buah ini berbentuk globe, dengan diameter 4-7 $\mathrm{cm}$ dan memiliki kelopak dengan ketebalan 4-6 $\mathrm{mm}$ dan berwarna ungu ketika matang (Paull and Ketsa 2014). Manggis memiliki kulit rasa pahit, latek kekuningan, dan pewarna ungu, isinya putih dengan 4-8 segmen dengan 2 segmen lebih besar dibandingkan yang lainnya yang mengandung biji yang dapat tumbuh (Paull and Ketsa 2014).

\section{METODOLOGI}

Gambar 4 menunjukkan diagram alir penelitian. Survey lapangan meliputi survey ketersediaan dan harga buah manggis, peralatan grading/grading yang ada, serta kunjungan ke instansi terkait.

Bahan yang digunakan dalam penelitian ini antara lain:

$$
\begin{array}{ll}
\text { - } & \text { Logam pejal } \\
\text { - } & \text { Logam hollow } \\
\text { - } & \text { Plat } \\
\text { - } & \text { Baut } \\
\text { - } & \text { Elektroda las } \\
\text { - } & \text { Saklar } \\
\text { - } & \text { Kabel } \\
\text { - } & \text { Kayu } \\
\text { - } & \text { Dempul } \\
\text { - } & \text { Cat } \\
\text { - } & \text { Motor listrik }
\end{array}
$$

Peralatan yang diperlukan dalam penelitian ini adalah sebagai berikut:

- Tachometer

- Penggaris

- Timbangan digital

- Busur derajat 
- Pemotong plat

- Tap

- Mesin las

- Mesin pemotong kayu

- Mesin bubut

- Komputer dilengkapi interface

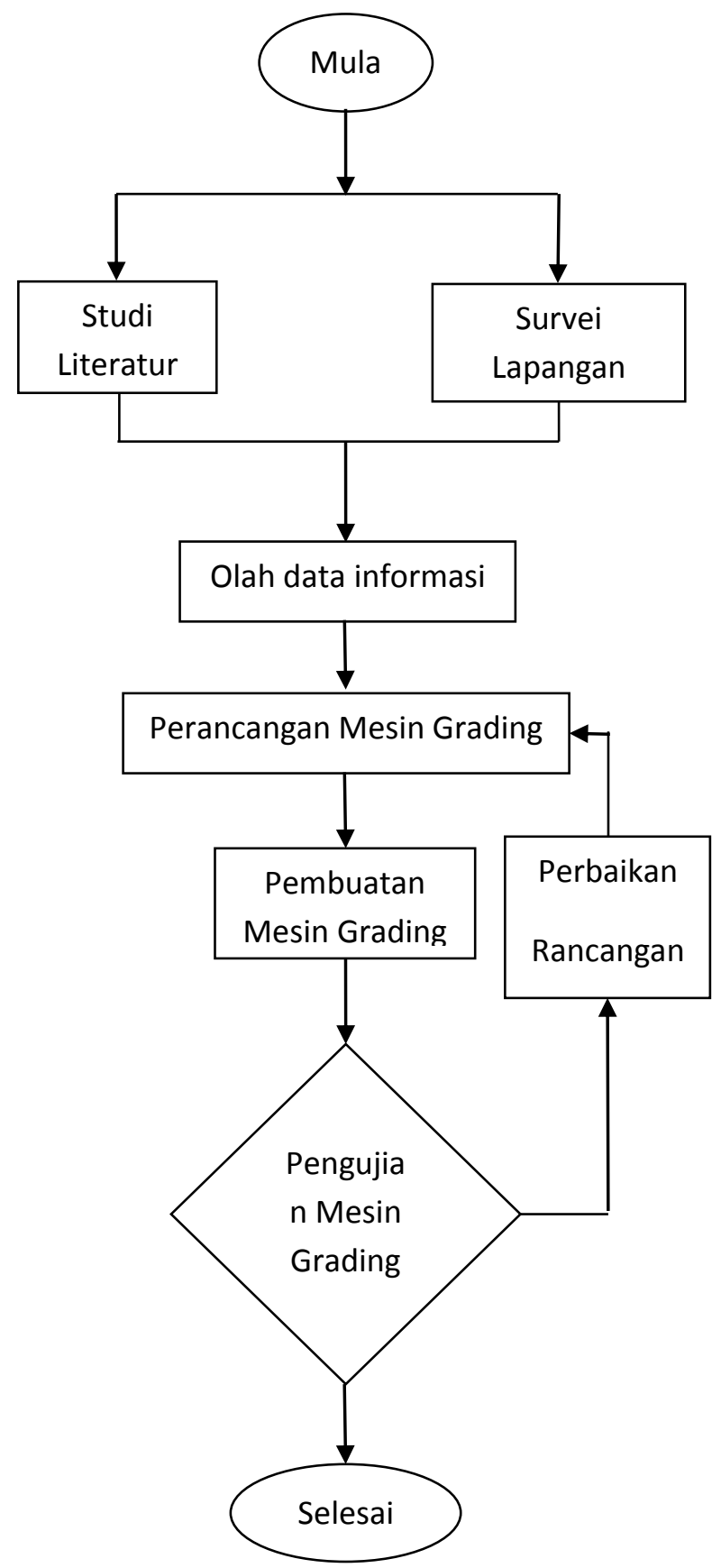

Gambar 4. Diagram alir penelitian

Setelah pembuatan mesin grading selesai, selanjutnya dilakukan pengujian unjuk kerjanya. Pengujian dilakukan dengan variasi kecepatan putar piringan. Buah manggis yang di-grading diumpankan ke mesin grading dikondisikan buah dapat jatuh ke piringan satu persatu.

Hasil pengujian dianalisis dengan persamaan (Jarimopas, Inprasit, and Toomsaengtong 2007):

$\overline{C_{R}}=\frac{\sum N_{i j}}{\sum N_{i}}$

Dengan

$\overline{C_{R}} \quad$ : Rasio kontaminasi

Nij : jumlah manggis grade i yang masuk

ke

tray penerima $j$

$\sum N i \quad$ : jumlah total manggis

$Q=\frac{W_{t}}{t}$

Dengan

$Q \quad$ : Kapasitas grading

$W_{t} \quad$ : jumlah masa total manggis yang digrading

$t \quad$ : waktu grading

Penelitian dilakukan di BBLM pada tahun 2016.

\section{HASIL DAN PEMBAHASAN}

Dari studi lapangan ke Dinas Tanaman Pangan Propinsi Jawa Barat diperoleh informasi hal-hal berikut. Buah manggis Indonesia dapat masuk ke negara lain seperti Australia, China dengan syarat bahwa buah dihasilkan dari kebun yang telah teregistrasi. Registrasi dilakukan oleh Dinas Tanaman Pangan. Selain itu, negara pengimpor manggis Indonesia mensyaratkan mutu dengan aturan yang berbeda satu dengan negara lain. China mensyaratkan tidak ada semut di buah manggis. Negara lainnya mensyaratkan usia panen tertentu. Di Amerika Serikat maupun internasional tidak ada standar grading manggis. Buah digrading berdasarkan warna dan ukuran.

Buah manggis yang berkualitas baik memiliki ciri-ciri sepal lengkap, warna kulit sesuai indeks kematangan tahap 3 dan 4 untuk tujuan ekspor. Berdasarkan informasi dari Seksi Perkebunan di Sukabumi, grading secara manual dapat mencapai kecepatan 500 kg/hari/org. Grading dan grading dilakukan 6-9 orang per hari. Dengan asumsi jam kerja selama 7 jam, maka kecepatan grading manual sekitar 71,4 kg/jam.

Perancangan mesin grading dibuat untuk dapat men-grading buah manggis berdasarkan 
diameter. Mesin grading menggunakan piringan berputar yang terbuat dari kayu mahoni(Gambar 5).

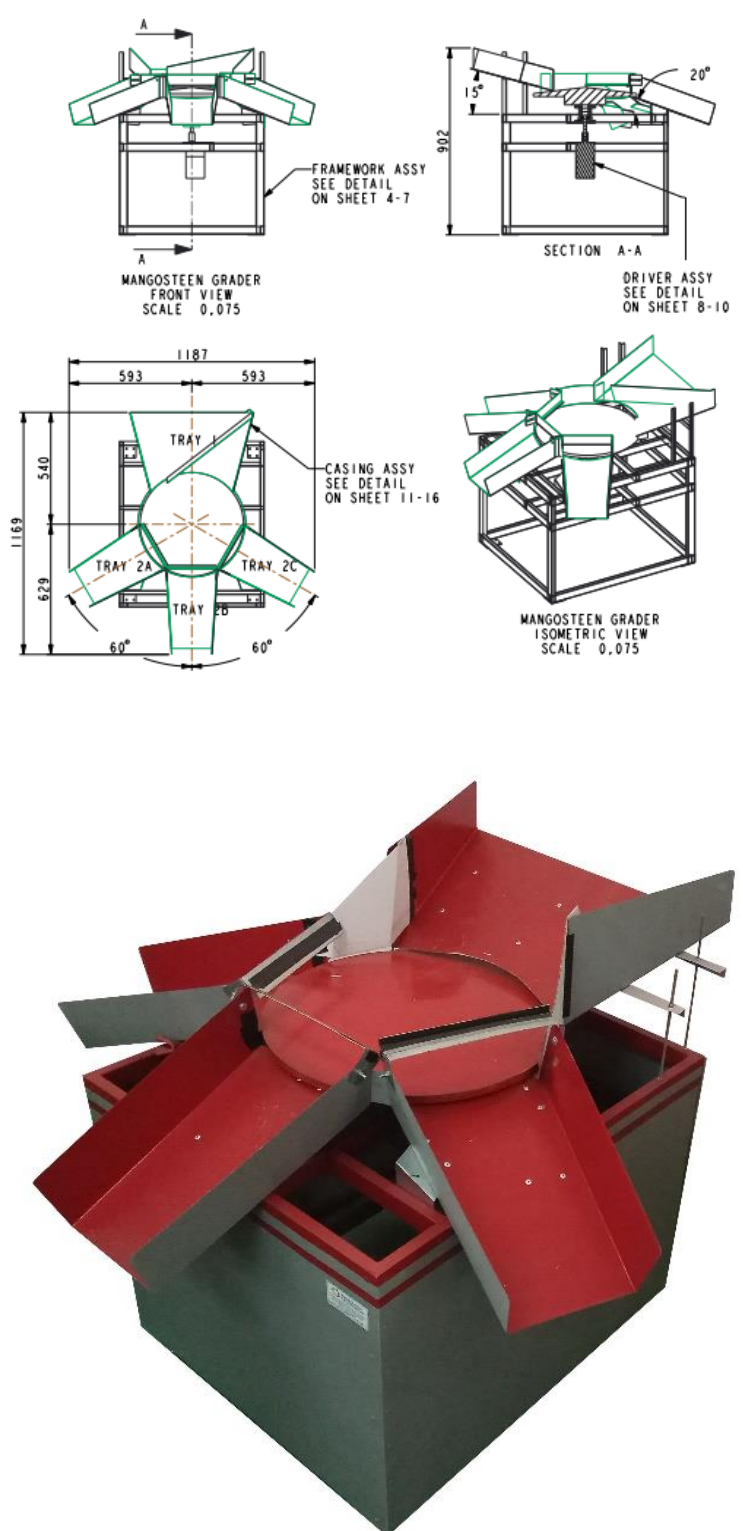

Gambar 5. Mesin grading manggis tipe piringan

Berdasarkan SOP pasca panen buah manggis 2013, maka dapat dilakukan grading berdasarkan ukuran diameter seperti ditunjukkan di Tabel III.

Tabel 3. Aturan Grading Buah Manggis

\begin{tabular}{|l|r|r|r|r|r|r|}
\hline Grade & \multicolumn{2}{|c|}{ A } & \multicolumn{2}{|c|}{ AA } & \multicolumn{2}{|c|}{ AAA } \\
\hline min & 6 & 6,92 & 10 & 100 & 14 & 2,96 \\
max & 8 & 125 & 13 & 3,17 & 15 & 2,75 \\
satuan & buah & gram & buah & gram & buah & gram \\
\hline Aturan & \multicolumn{1}{|c|}{125} & $75<\mathrm{x} \leq 125$ & $\leq 71.5$ \\
\hline & gram & \multicolumn{2}{|c|}{ gram } & gram \\
\hline Diameter $(\mathbf{m m})$ & \multicolumn{2}{|c|}{$>64$} & \multicolumn{2}{|c|}{$53<\mathrm{x} \leq 64$} & $\leq 53$ \\
\hline
\end{tabular}

Celah pada mesin grading buah manggis ditunjukkan dalam Gambar 6 sampai Gambar 8 .

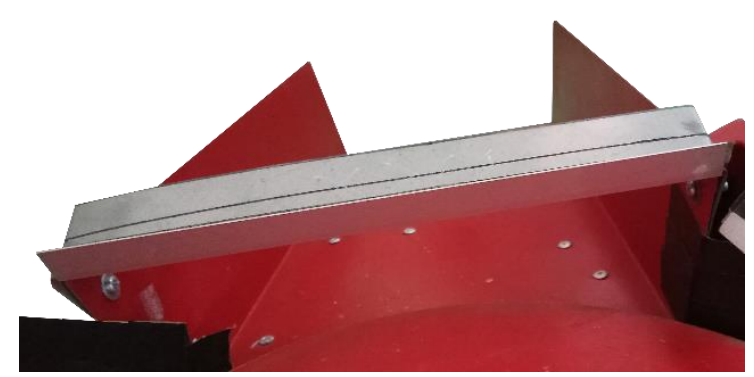

Gambar 6. Celah Grade A

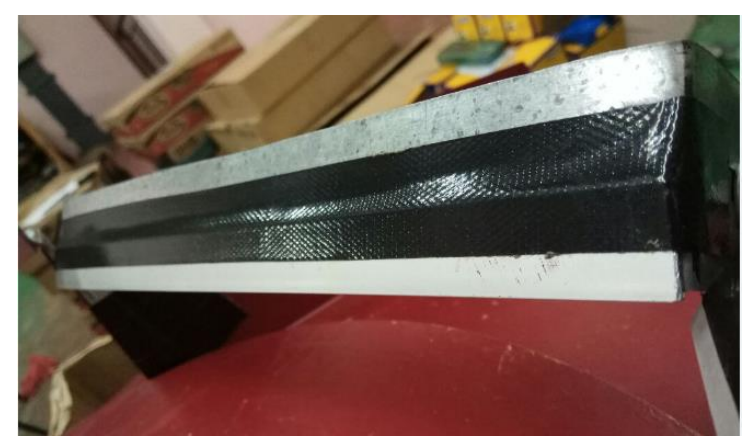

Gambar 7. Celah Grade AA

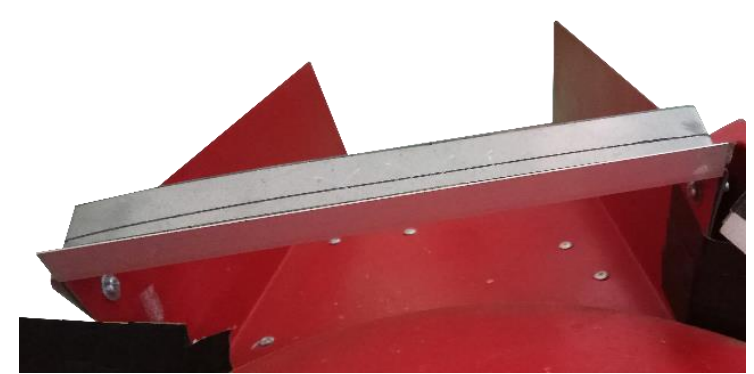

Gambar 8. Celah Grade AAA

Pengujian dilakukan dengan variasi kecepatan rotating piringan. Tabel IV menunjukkan kecepatan rotating piringan yang diukur dengan menggunakan tachometer.

Tabel 4. Kecepatan Rotasi Piringan Mesin Grading Buah Manggis

\begin{tabular}{|c|c|}
\hline Kecepatan & Rpm \\
\hline I & 12,2 \\
\hline II & 30,3 \\
\hline III & 44,7 \\
\hline IV & 51,9 \\
\hline V & 61,8 \\
\hline VI & 68,4 \\
\hline
\end{tabular}

Pengujian mesin dengan kecepatan I sampai dengan VI menghasilkan data Tabel V sampai dengan Tabel X 
Tabel 5. Tabel hasil pengujian mesin grading buah manggis kecepatan I

\begin{tabular}{|c|c|c|c|}
\hline $\begin{array}{r}\text { Ukuran } \\
\text { Mesin } \\
\text { Grading }\end{array}$ & A & AA & AAA \\
\hline A & 3 & 4 & 3 \\
\hline AA & 1 & 18 & 21 \\
\hline AAA & 0 & 0 & 0 \\
\hline
\end{tabular}

Tabel 6. Tabel hasil pengujian mesin grading buah manggis kecepatan II

\begin{tabular}{|c|c|c|c|}
\hline $\begin{array}{r}\text { Ukuran } \\
\text { Mesin } \\
\text { Grading }\end{array}$ & A & AA & AAA \\
\hline A & 3 & 7 & 0 \\
\hline AA & 0 & 24 & 16 \\
\hline AAA & 0 & 0 & 0 \\
\hline
\end{tabular}

Tabel 7. Tabel hasil pengujian mesin grading buah manggis kecepatan III

\begin{tabular}{|c|c|c|c|}
\hline $\begin{array}{l}\text { Ukuran } \\
\text { Mesin } \\
\text { Grading }\end{array}$ & A & AA & AAA \\
\hline A & 2 & 8 & 0 \\
\hline AA & 0 & 29 & 11 \\
\hline AAA & 0 & 0 & 0 \\
\hline
\end{tabular}

Tabel 8. Tabel hasil pengujian mesin grading buah manggis kecepatan IV

\begin{tabular}{|c|c|c|c|}
\hline $\begin{array}{l}\text { Ukuran } \\
\text { Grading }\end{array}$ & A & AA & AAA \\
\hline A & 5 & 2 & 3 \\
\hline AA & 1 & 27 & 12 \\
\hline AAA & 0 & 0 & 0 \\
\hline
\end{tabular}

Tabel 9. Tabel hasil pengujian mesin grading buah manggis kecepatan $\mathrm{V}$

\begin{tabular}{|c|c|c|c|}
\hline $\begin{array}{l}\text { Hasil } \\
\text { Grading }\end{array}$ & A & AA & AAA \\
\hline A & 9 & 1 & 0 \\
\hline AA & 11 & 22 & 7 \\
\hline AAA & 0 & 0 & 0 \\
\hline
\end{tabular}

Tabel 10. Tabel hasil pengujian mesin grading buah manggis kecepatan VI

\begin{tabular}{|c|c|c|c|}
\hline $\begin{array}{r}\text { Ukuran } \\
\text { Mesin } \\
\text { Hasil } \\
\text { Grading }\end{array}$ & A & AA & AAA \\
\hline A & 9 & 1 & 0 \\
\hline AA & 11 & 22 & 7 \\
\hline AAA & 0 & 0 & 0 \\
\hline
\end{tabular}

Dari data Tabel V sampai IX maka diperoleh rasio kontaminasi $\left(\overline{C_{R}}\right)$ dengan persamaan (1) seperti yang ditunjukkan di Tabel XI.

Tabel XI. Rasio Kontaminasi

Tabel 11. Rasio Kontaminasi

\begin{tabular}{|c|c|}
\hline Kecepatan & rasio kontaminasi $\left(\overline{C_{R}}\right)$ \\
\hline I & $58 \%$ \\
\hline II & $46 \%$ \\
\hline III & $38 \%$ \\
\hline IV & $36 \%$ \\
\hline V & $38 \%$ \\
\hline VI & $32 \%$ \\
\hline
\end{tabular}

Dari enam variasi kecepatan rotasi piringan, kecepatan keenam menghasilkan rasio kontaminasi terkecil. Berdasarkan hasil ini maka dilakukan 4 kali pengulangan pengujian mesin grading. Tabel XII menunjukkan hasil ratio kontaminasi dengan perhitungan menggunakan persamaan (1). Berdasarkan hasil pengukuran dan perhitungan dengan persamaan (2) diperoleh kapasitas mesin (Q) rata-rata senilai $641,015 \mathrm{~kg} / \mathrm{jam}$.

Tabel 12.Rasio Kontaminasi pada Kecepatan Rotasi VI

\begin{tabular}{|c|c|}
\hline $\begin{array}{c}\text { Pengujian } \\
\text { ke- }\end{array}$ & $\begin{array}{c}\text { rasio kontaminasi } \\
\left(\overline{C_{R}}\right)\end{array}$ \\
\hline 1 & $32 \%$ \\
\hline 2 & $46,8 \%$ \\
\hline 3 & $16,3 \%$ \\
\hline 4 & $31,2 \%$ \\
\hline Rata-rata & $31,6 \%$ \\
\hline $\begin{array}{c}\text { Standar } \\
\text { Deviasi }\end{array}$ & $12,46 \%$ \\
\hline
\end{tabular}

Setiap pengujian diamati hal-hal berikut. Pertama,kondisi gerak rotasi piringan. Kedua, jatuhnya buah manggis di piringan celah grading. Terakhir, perubahan tinggi celah 
grading. Dari pengamatan menunjukkan adanya ketidaksabilan posisi piringan, manggis jatuh ke disk tidak terus menerus satu persatu, dan celah grading berubah tingginya. Perubahan tinggi celah grading disebabkan gerakan buah manggis yang saling mendorong satu dengan yang lain dan pengunci celah yang kurang baik.

Hasil penelitian ini diharapkan dapat bermanfaat untuk pengembangan mesin grading buah manggis yang memenuhi standar. Hasil penelitian ini dapat diaplikasikan dan dimanfaatkan oleh petani, pengekspor buah manggis dan industri mesin grading buah maupun industri kecil dan menengah pengolah buah manggis di Indonesia.

\section{KESIMPULAN}

Penelitian grading buah manggis ini telah menghasilkan prototipe mesin grading buah manggis berdasarkan diameter buah manggis. Grade buah manggis adalah A dengan diameter (D) $>64 \mathrm{~mm}$, AA dengan $53 \mathrm{~mm}<\mathrm{D} \leq 64 \mathrm{~mm}$, dan AAA dengan $\mathrm{D} \leq 53 \mathrm{~mm}$. Pengujian dilakukan dengan variasi kecepatan putar piringan. Hasil yang terbaik adalah pada putaran piringan 68,4 rpm. Dengan putaran piringan tersebut, diperoleh kapasitas mesin rata-rata senilai $641,015 \mathrm{~kg} / \mathrm{jam}$. Hasil pengujian menunjukkan bahwa prototipe mesin grading buah manggis sudah dapat berfungsi memisahkan buah manggis sesuai dengan grade-nya. rasio kontaminasi rata-rata sebesar $31,6 \%$ dengan standar deviasi $12,46 \%$. Besarnya penyebaran nilai rasio kontaminasi dipengaruhi oleh faktor konstruksi dudukan motor, sistem pengumpan, dan celah grading.

\section{UCAPAN TERIMA KASIH}

Penulis mengucapkan terima kasih kepada Ir. Eddy Siswanto, MAM sebagai Kepala Balai Besar Logam dan Mesin atas terselenggaranya penelitian ini.

\section{DAFTAR PUSTAKA}

Badan Standardisasi Nasional. 2009. "Sni 32112009: Manggis."

Fager, George. 1918. "Studies on Mechanical Fruit Grading Machines." University of Illinois.

Gao, Haisheng, Jinxing Cai, and Xiufeng Liu. 2010. "Automatic Grading of the PostHarvest Fruit: A Review." IFIP Advances in Information and Communication Technology $\quad 317:$ 141-46. doi:10.1007/978-3-642-12220-0_22.

Jarimopas, Bundit, Chouw Inprasit, and Siam Toomsaengtong. 2007. "Design and Testing of a Mangosteen Fruit Sizing Machines." AMA, Agricultural Mechanization in Asia, Africa and Latin $\begin{array}{lll}\text { America } & 38 & \text { (4): } 42-46 .\end{array}$ doi:10.1016/j.jfoodeng.2006.01.083.

Kementan RI. 2014. "Renstra Kementrian Pertanian Pertanian Tahun 2015 - 2019," 1-339. doi:351.077 Ind r.

Markovic, D.D., N.S. Mladenovic, V.D. Simonovic, and I.M. Markovic. 2014. "Modeling the Motion and Mass Quantity of Fruit by Rotating Sizing Machines." FME Transactions 42 (1). doi:10.5937/fmet1401034M.

Paull, Robert E, and Saichol Ketsa. 2014. "Mangosteen: Postharvest QualityMaintenance Guidelines," no. September: 30-32.

Tabatabaekoloor, Reza, and Jafar Hashemi. 2008. "Development and Evaluation of a Citrus Sorting Machine with Rotary SemiConical Disc." Jurnal of Agricultural Machinery Science 4 (4): 371-74. 